Abstracted/indexed in Academic Search Complete, Asia Journals Online, Bangladesh Journals Online, Biological Abstracts, BIOSIS Previews, CAB Abstracts, Current Abstracts, Directory of Open Access Journals, EMBASE/Excerpta Medica, Google Scholar, HINARI (WHO), International Pharmaceutical Abstracts, Open J-gate, Science Citation Index Expanded, SCOPUS and Social Sciences Citation Index;

ISSN: $1991-0088$

\title{
Condensation reaction of benzil with resorcinol and the establishment of the spectral data as well as cytotoxicity study
}

\section{A. Kashem Liton and M. Rabiul Islam}

Department of Chemistry, Jahangirnagar University, Savar, Dhaka 1342, Bangladesh.

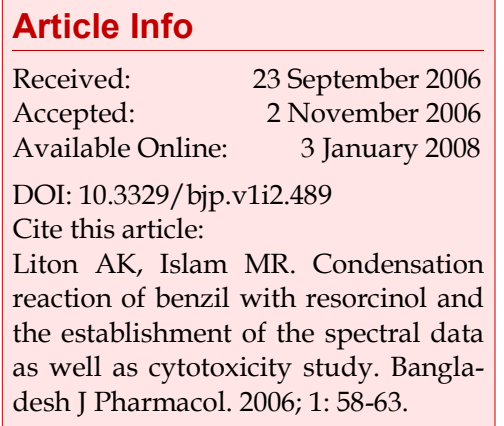

\section{Abstract}

Condensation of benzil, 1 with resorcinol in the presence of potassium carbonate at $110-120^{\circ} \mathrm{C}$ gave the mixture of the compounds. Using various kinds of separation technique only five types of the polymeric products, a1, a2, a3, a4 and a5 were isolated. The compounds a1, a4 showed high cytotoxic activity and the compounds a2, a3 and a5 showed relatively low cytotoxic activity against the brine shrimp lethality bioassay.

\section{Introduction}

Various types of substituted heterocyclic compounds were synthesized and cytotoxic activity of these compounds have been found by screening tests (Islam et al., 2001a; Islam et al., 2001b; Lingcon et al., 2001). To compare the cytotoxic activity of the titled compounds in scheme 1 have been isolated and sent for screening tests whether they can show reasonable lethal effect on brine shrimp (Anderson et al., 1999) or not. The compounds that are mentioned have been furnished in Scheme 1 with Flow-chart 1.

\section{Materials and Methods}

Melting points were not corrected. IR spectra were recorded on a Shimadzu DR 8001 FT-IR spectrometer, NMR spectra on a WP 200 spectrometer using TMS as internal standard and mass spectra on an MS Kratas mass spectrometer.

\section{Reaction}

Benzil (0.01 moles or $2.10 \mathrm{gm})$, resorcinol (0.005 moles or $0.55 \mathrm{gm})$ and potassium carbonate $(0.015$ moles or
$2.07 \mathrm{gm}$ ) were mixed and heated in three necked quickfit round bottom flask in the oil bath at $110-120^{\circ} \mathrm{C}$. Heat was continued until all the solids were melted to liquid and this liquid was heated for half an hour. $\mathrm{CO}_{2}$ was evolved and this liquid was converted into colored solid mass. This solid contains mixture of compounds (Hans et al., 1905), PM that was examined on TLC.

\section{Extraction of the compound (a1)}

Chloroform was mixed to the water-soluble portion and shaken half an hour. Two layers were formed. Lower layer was organic layer and upper layer was aqueous layer. Thus yellow organic layer was collected in several times and dried over anhydrous $\mathrm{Na}_{2} \mathrm{SO}_{4}$. This organic layer was evaporated and it gives a single product, a1, m.p. $110-13^{\circ} \mathrm{C}$. Its color is red. IR: $\mathrm{v}^{\text {Nujol }}$ $\left(\mathrm{cm}^{-1}\right)$ 3500-2500 (b, H bonded $\mathrm{OH}$ of $\mathrm{COOH}$ ); 2955, 2926 (vC-H); 1605 (b, vC=O); 1207 (b, vC-O stretching). 1H-NMR (DMSO): $\delta$ 10.20-9.80 (b, COOH), $\delta 8.50-8.20$ (b, OH), 8.00-6.00 (m, C-H, aromatic protons). ${ }^{13} \mathrm{C}-\mathrm{NMR}$

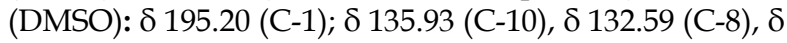
131.11 (C-7), ठ 129.97 (C-11), d 129.89 (C-3), d 129.62 (C15), d 129.33 (C-6), d 129.21 (C-4), d 128.90 (C-5), 128.00 $(\mathrm{C}-12)$ and $\delta 70.56(\mathrm{C}-9)$. Mass: $\mathrm{m} / \mathrm{z}$ (\% of relative 


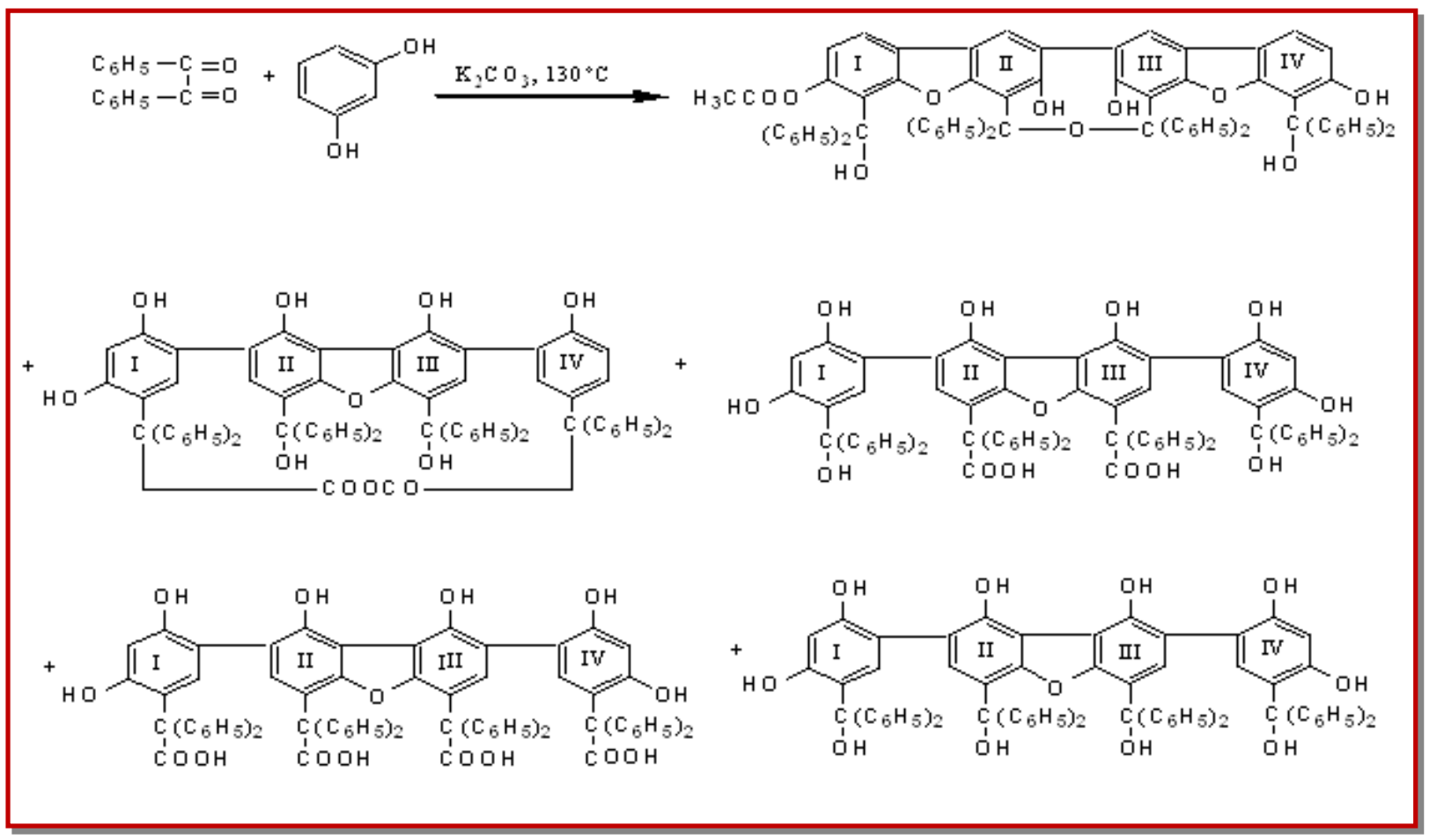

Scheme 1

intensity) $1256.0\left(\mathrm{M}^{+}, 2 \%\right), 873.0(15 \%), 677.0$ (55\%), $225.1(6 \%), 154.0(10 \%)$ and $105.0(100 \%)$. The molecular ion peak appears at $\mathrm{m} / \mathrm{z} 1256$ due to $\mathrm{C}_{80} \mathrm{H}_{56} \mathrm{O}_{15}$.

\section{Separation of the product (a2)}

The product, a2 was dried in desiccator and gave single spot on TLC examination, m.p. $258-60^{\circ} \mathrm{C}$. The color of the compound was light brick red. IR: $\mathrm{v}^{\text {Nujol }}\left(\mathrm{cm}^{-1}\right) 3200-$ 3600 (s, b, vOH); 3087, 3056 (s, vC-H, aromatic); 1732, $1600(\mathrm{vC}=\mathrm{O}) ; 1565,1547(\mathrm{vC}=\mathrm{C}$, aromatic rings); 1212 (vC-O).

\section{Isolation of the compound (a3)}

After collecting the $\mathbf{P}_{\text {LDM }}$ product, this portion was separated by column chromatography on silica gel using pet ether and ethyl acetate. 0.639 gm was taken for separation. Different fractions were recorded and then later were evaporated. TLC examinations were shown in Table I.

\section{Identification of the $4^{\text {th }}$ fraction}

This portion was orange yellow in color yielded 0.080 gm and m.p $140-42^{\circ} \mathrm{C}$. This was designated as a3. IR: v Nujol (cm-1) 3600-3200 (b, vOH); 3025 (vC-H, aromatic); 1684, 1672 (vC=C, aromatic rings); 1277 (b, vC-O).

\section{Isolation of the compound (a4)}

Further separation of the $6^{\text {th }}$ fraction

The $6^{\text {th }}$ fraction in Table I was taken for PTLC method for further separation and pet ether and ethyl acetate were used as solvent (EA:PE=3:2). Three bands were found in Table II.

$3^{\text {rd }}$ band that collected was designated as a4. The product was solid (light pink color). IR: $\mathrm{v}^{\text {Nujol }}\left(\mathrm{cm}^{-1}\right)$ 3600 - 3200 (b, vOH (H bonded of $\mathrm{COOH}$ ) group); 3060, 3028 (vC-H, aromatic); 1799, 1714 (b, vC=O); 1601 ( $\mathrm{vC}=\mathrm{C}$, aromatic rings); 1277 (b, vC-O stretching).

\section{Isolation of the compound (a5)}

After getting the $\mathbf{P}_{\text {ETR }}$ product this portion was separated by column chromatography on silica gel using ethyl acetate and pet ether. $1.0 \mathrm{gm}$ was taken for separation. Different fractions were collected and evaporated for the TLC examination, which were given in Table III.

\section{Further separation of the $4^{\text {th }}$ fraction}

The $4^{\text {th }}$ fraction was taken for PTLC method for further separation and pet ether and ethyl acetate were used as solvent (EA:PE=5:95). Three bands were found in Table IV.

$2^{\text {nd }}$ band was collected and was designated as a5. The product was solid, m.p. $287-88^{\circ} \mathrm{C}$.

IR: $\mathrm{v}^{\text {Nujol }}\left(\mathrm{cm}^{-1}\right)$ 3600-3300 (b, vOH, stretching); 3063, 3050 (vC-H, aromatic); 2980 (vC-H, aliphatic); 1809, 1740 (b, vC=O asymmetric and symmetric stretching); 1597, 1581 (vC=C, aromatic rings); 1211 (vC-O). ${ }^{1} \mathbf{H}-$ NMR (DMSO): $\delta$ 8.20-8.00 (b, OH, phenol), $\delta ~ 7.90-7.10$ (m, C-H, aromatic protons), $\delta$ 6.40-6.20 (s, OH, alcohol), 


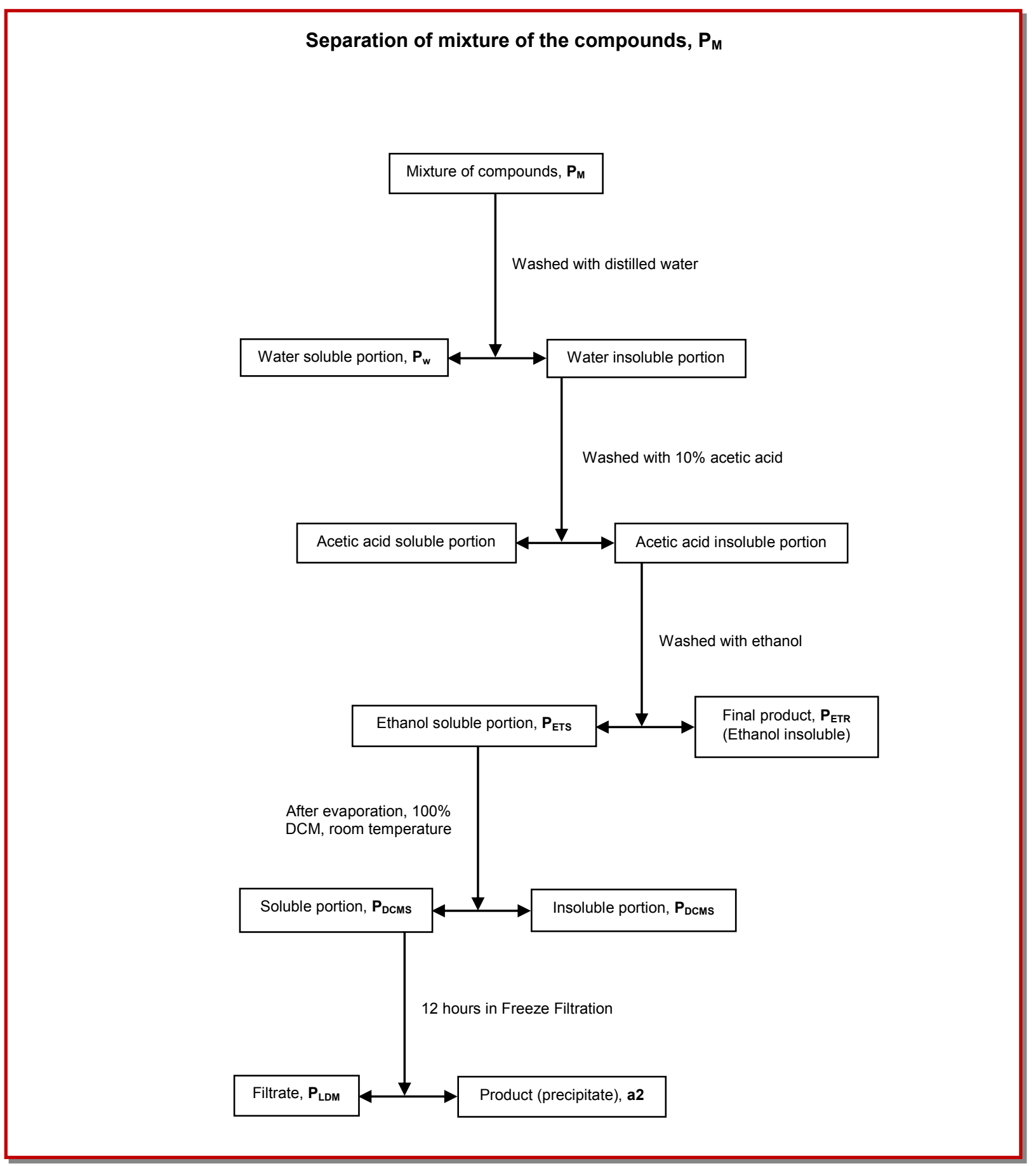

Flow Chart

$\delta 2.30$ (s, 3H, $\mathrm{CH}_{3}$, aliphatic). Mass: $\mathrm{m} / \mathrm{z}$ (\% of relative intensity) 677.0 (18\%), 483.1 (25\%), 307.1 (22\%) and $154.0(100 \%)$. The molecular ion peak appears at $\mathrm{m} / \mathrm{z}$ 1150 due to $\mathrm{C}_{78} \mathrm{H}_{54} \mathrm{O}_{10}$.

\section{Results and Discussion}

The mixture of the products, $\mathbf{P}_{\mathbf{M}}$ was washed with water and then this water soluble portion was extracted by chloroform and TLC examination of the product, a1 showed the single spot. In the IR spectrum of the compound a1, the broad band at $3500-2500 \mathrm{~cm}^{-1}$ points out the presence of $\mathrm{H}$-bonded $\mathrm{OH}$ of $\mathrm{COOH}$ (i.e., presence of $\mathrm{COOH}$ group and $\mathrm{OH}$ group of aromatic in $\mathrm{H}$-bonding). The signal at $2955 \mathrm{~cm}^{-1}$ indicates the presence of $\mathrm{C}-\mathrm{H}$ group in aromatic ring. The value of $\mathrm{d}_{\mathrm{H}}$ is lowered due the H-bonded. The weak band at 1605 


\section{Table I}

Several fractions that were recorded during column chromatography

\begin{tabular}{|lll|}
\hline Fractions & \multicolumn{1}{c|}{ Color } & \multicolumn{1}{c|}{ TLC examination and $\mathrm{R}_{\mathrm{f}}$ value } \\
\hline $1^{\text {st }}$ fraction (1-5) & --- & --- \\
$2^{\text {nd }}$ fraction (6-13) & Light yellow & One spot, 0.73 , benzil (reactant) \\
$3^{\text {rd }}$ fraction (14-18) & Light orange & Three spots having reactant \\
$4^{\text {th }}$ fraction (19-29) & Orange yellow & One spot, 0.35 \\
$5^{\text {th }}$ fraction (30-34) & Light green & One spot with tailing \\
$6^{\text {th }}$ fraction $(35)$ & Slightly yellow & Two spot, $0.35,0.81$ \\
$7^{\text {th }}$ fraction $(36-42)$ & Yellow orange & Three spots with tailing \\
$8^{\text {th }}$ fraction $(43-48)$ & Light yellow orange & Three spots having too much tailing \\
\hline
\end{tabular}

\begin{tabular}{|lll|}
\hline \multicolumn{2}{|c|}{ Table II } \\
\hline & & Different bands in TLC \\
\hline Name & Amount & R $_{\mathrm{f}}$ value \\
\hline $1^{\text {st }}$ band & Trace amount & Discarded \\
$2^{\text {nd }}$ band & $3 \mathrm{mg}$ & Three spots with tailing \\
$3^{\text {rd }}$ band & $4 \mathrm{mg}$ & One spot, 0.81 \\
\hline
\end{tabular}

Table III

Different fractions that were recorded during column chromatography

\begin{tabular}{|lclcc|}
\hline \multicolumn{1}{|c}{ Fraction no } & Test tube no & \multicolumn{1}{c|}{ Color } & Amount & TLC exam. \& $\mathrm{R}_{\mathrm{f}}$ value \\
\hline $1^{\text {st }}$ fraction & $1-4$ & ---- & ---- & --- \\
$2^{\text {nd }}$ fraction & $5-10$ & Light yellow & $0.05 \mathrm{~g}$ & 0.95 , it may reactant (benzil) \\
$3^{\text {rd }}$ fraction & $11-18$ & Reddish & $0.08 \mathrm{~g}$ & $0.95,0.90$ \\
$4^{\text {th }}$ fraction & $19-21$ & Brown & $0.03 \mathrm{~g}$ & 0.90 , one spot with tailing \\
$5^{\text {th }}$ fraction & $22-28$ & Red & $0.10 \mathrm{~g}$ & Too many spots \\
$6^{\text {th }}$ fraction & $29-50$ & Deep red & 0.15 & Too many spots \\
$7^{\text {th }}$ fraction & $51-70$ & Yellow & 0.17 & Too many spots \\
$8^{\text {th }}$ fraction & $71-90$ & Yellow & 0.21 & Too many spots \\
\hline
\end{tabular}

Table IV

\section{Different bands in TLC}

\begin{tabular}{|lll|}
\hline Name & Amount & $R_{\mathrm{f}}$ value \\
\hline $1^{\text {st }}$ band & Trace amount & Discarded \\
$2^{\text {nd }}$ band & $8 \mathrm{mg}$ & 0.90 (one spot) \\
$3^{\text {rd }}$ band & $5 \mathrm{mg}$ & $0.90,0.88$ tailing \\
\hline
\end{tabular}

$\mathrm{cm}^{-1}$ identifies $\mathrm{C}=\mathrm{O}$ group in $\mathrm{COOH}$ and the value at $1288 \mathrm{~cm}^{-1}$ indicates the presence of $\mathrm{C}-\mathrm{O}$ group. In ${ }^{\mathbf{1}} \mathbf{H}-$ NMR spectrum, the broad signal (hum) at $\delta 10.2-9.8$ is assigned for $\mathrm{COOH}$ and the other broad value at $\mathrm{d} 8.5$ -
8.2 indicates the presence of $\mathrm{OH}$ group in aromatic. The multiplet at 8.0 - 6.0 shows the presence of the rest of $C$ $\mathrm{H}$ protons in aromatic ring. In ${ }^{13} \mathrm{C}-\mathrm{NMR}$ spectrum, the peak at $\delta 195.20$ (C-1) is assigned for the carbonyl 
group, $\mathrm{C}=\mathrm{O}$ in $\mathrm{COOH}$. The aromatic carbons are designated by the following values $\delta 135.93(\mathrm{C}-10), \delta$

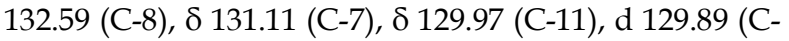
3), d 129.62 (C-15), d 129.33 (C-6), d 129.21 (C-4), d 128.90 (C-5), 128.00 (C-12) and $\delta 70.56$ (C-9). In the mass spectrum, molecular ion peak $\left(\mathrm{M}^{+} 2 \%\right)$ appears at $\mathrm{m} / \mathrm{z}$ 1256 that corresponding to the molecular formula $\mathrm{C}_{80} \mathrm{H}_{56} \mathrm{O}_{15}$. In this spectrum the base peak is formed at $\mathrm{m} / \mathrm{z} 105$.

The product, a2 was obtained from the cold precipitate of DCM soluble portion and this DCM soluble portion was found from ethanol soluble portion of $\mathbf{P}_{\mathbf{M}}$. This product gave the single spot on TLC examination. In the IR spectrum of the compound, a 2 the broad band at 3600 - $3200 \mathrm{~cm}^{-1}$ indicates the presence of $\mathrm{OH}$ group. The signals at $3087 \mathrm{~cm}-1,3056 \mathrm{~cm}-1$ indicate the presence of $\mathrm{C}-\mathrm{H}$ group in aromatic ring. The values at $1732 \mathrm{~cm}^{-1}, 1600 \mathrm{~cm}^{-1}$ show the presence of $\mathrm{C}=\mathrm{O}$ group in CO-O-CO. The bands at $1565 \mathrm{~cm}^{-1}$ and $1547 \mathrm{~cm}^{-1}$ indicate the presence of $\mathrm{C}-\mathrm{H}$ group of aromatic ring. The weak band at $1212 \mathrm{~cm}^{-1}$ also identifies the existence of C-O group.

After collecting the cold filtrate, $\mathbf{P}_{\text {LDM }}$ of DCM soluble portion that obtained from ethanol soluble portion of $\mathbf{P}_{\mathbf{M}}$ and this portion $\left(\mathrm{P}_{\mathrm{LDM}}\right)$ was separated by column chromatography on silica gel using pet ether and ethyl acetate. $0.639 \mathrm{gm}$ was taken for separation. Different fractions were recorded and from these fractions, the $4^{\text {th }}$ and $6^{\text {th }}$ fractions were collected. The $4^{\text {th }}$ portion was orange yellow colored and this portion was designated as a3. In the IR spectrum of the compound, a3 the broad band at $3600-3200 \mathrm{~cm}^{-1}$ indicates the presence of $\mathrm{OH}$ group. The signal at $3025 \mathrm{~cm}^{-1}$ indicates the presence of $\mathrm{C}-\mathrm{H}$ group in aromatic ring. The bands at $1684 \mathrm{~cm}^{-1}$ and $1672 \mathrm{~cm}^{-1}$ indicate the presence of $\mathrm{C}-\mathrm{H}$ group in aromatic ring. The weak band at $1277 \mathrm{~cm}^{-1}$ also identifies the existence of C-O group.

The $\mathbf{6}^{\text {th }}$ fraction was taken for PTLC method for further separation. Pet. ether and ethyl acetate were used as solvents (EA:PE=3:2). Here 3 bands were found. $3^{\text {rd }}$ band that collected was designated as a4. The product was light pink color. In the IR spectrum of the compound a4 the broad band at $3600-3200 \mathrm{~cm}^{-1}$ indicates the presence of $\mathrm{OH}$ group. The signals at 3060 $\mathrm{cm}-1,3028 \mathrm{~cm}-1$ indicate the presence of $\mathrm{C}-\mathrm{H}$ group in aromatic ring. The values at $1799 \mathrm{~cm}^{-1}$ and $1714 \mathrm{~cm}^{-1}$ show the presence of $\mathrm{C}=\mathrm{O}$ group in $\mathrm{COOH}$. The band at $1601 \mathrm{~cm}^{-1}$ indicates the presence of $\mathrm{C}-\mathrm{H}$ group of aromatic ring. The weak band at $1277 \mathrm{~cm}^{-1}$ also identifies the existence of $\mathrm{C}-\mathrm{O}$ group.

After getting the ethanol insoluble portion, $\mathbf{P}_{\mathbf{E T R}}$ this portion was separated by column chromatography on silica gel using ethyl acetate and pet ether. $1.0 \mathrm{gm}$ was taken for separation. Different fractions were recorded, from these fractions only $4^{\text {th }}$ fraction was collected and it was taken for PTLC method for further separation. Pet.ether and ethyl acetate were used as solvents (EA:PE=5:95). Here 3 bands were found. $2^{\text {nd }}$ band was collected that designated as a5. In the IR spectrum of the compound, a5 the broad band at $3600-3300 \mathrm{~cm}^{-1}$ indicates the presence of $\mathrm{OH}$ group. The signals at 3063 $\mathrm{cm}-1,3050 \mathrm{~cm}-1$ indicate the presence of $\mathrm{C}-\mathrm{H}$ group in aromatic ring. The value at $2980 \mathrm{~cm}^{-1}$ shows the presence of $\mathrm{C}-\mathrm{H}$ in saturated aliphatic. The bands at 1809 and $1740 \mathrm{~cm}^{-1}$ indicate the presence of $\mathrm{C}=\mathrm{O}$ group (asymmetric and symmetric stretching). The values at 1597 and $1581 \mathrm{~cm}^{-1}$ exhibit $\mathrm{C}=\mathrm{C}$ group in aromatic ring. The sharp band at $1211 \mathrm{~cm}^{-1}$ also identifies the existence of C-O group. In ${ }^{\mathbf{1}} \mathbf{H}-\mathbf{N M R}$ spectrum the broad peak shows the singlet at $\delta 8.2-8.0$ which would be assigned for $\mathrm{OH}$ protons of phenol type compounds. The multiplet at $\mathrm{d} 7.9$ - 7.1 indicates the presence of $\mathrm{C}-\mathrm{H}$ protons in aromatic rings. The two singlets at $\mathrm{d} 6.3$ and d 6.2 indicate the presence of two $\mathrm{OH}$ groups. The singlet at 2.3 indicates the presence of $\mathrm{CH}_{3}$ group in $\mathrm{CH}_{3}-\mathrm{CO}-\mathrm{O}$. In the MS spectrum of the compound, a5 molecular ion peak $\left(\mathrm{M}^{+} 1 \%\right)$ appears at $\mathrm{m} / \mathrm{z} 1150$ that corresponding to the molecular formula $\mathrm{C}_{78} \mathrm{H}_{54} \mathrm{O}_{10}$. In this spectrum the base peak is formed at m/z 154 .

\section{Cytotoxicity}

Cytotoxicity of all the compounds was measured by brine shrimp lethality bioassay method (Anderson et al., 1999) Cisplatin, a recognized anti-cancer drug was used as reference to compare the efficacy of the synthesized compounds. Compounds a1, a2, a3, a4 and a5 showed significant cytotoxicity. Compounds a1 and a4 showed high cytotoxicity. Compounds, a2, a3 and a5 showed relatively low cytotoxicity. So these compounds may show anti-microbial, anti-tumor etc. activity.

\section{Acknowledgement}

The authors express their sincere thanks to Khurshida Khayer Mamun, Department of Chemistry, Jahangirnagar University, Savar, Dhaka, Bangladesh for supplying ${ }^{1} \mathrm{H}-\mathrm{NMR},{ }^{13} \mathrm{C}-\mathrm{NMR}$ and Mass spectra of the compounds from Germany.

\section{References}

Anderson JE, Goetz CM, McLaughlin JL, Suffness M. Phytochemical analysis. Oxford University Press, $4^{\text {th }}$ ed. 1991, pp 107-10.

von Liebig H. Condensation reaction of benzil with resorcinol. J Prac Chem. 1905; 74: 345-59.

Islam MR, Khayer K, Mahmud MI. Reaction of Isatin with 2-aminothiophenol leading to spiroheterocyclic having anticancer activity. Jahangirnagar Univ J Sci. 2001a; 24: 17-22.

Islam R, Khayer K, Abedin MJ, Islam MR. Synthesis of (5-spiro 
(5'-methylisatin)-4-acetyl-2-(acetylamino) $\Delta-{ }^{-2}-, 3,4-$ thiadiazoline and 5-spiro (5'-methylisatin)-4-acetyl-2-(5'methylisatin-3'-hydrazineo)- $\Delta-{ }^{-2}-1,3,4$-thiadiazoline, Indian J Chem. 2001b; 40B: 240-42.
Lingcon MH, Islam R, Khayer K, Islam MR. Cyclization of substituted indole-2-one-3-thiosemicarbazones to noble heterocyclic systems. J Bangladesh Chem Soc. 2001; 14: 12732.

\section{Author Info}

M. Rabiul Islam (Principal contact) I e-mail: rabiulju@gmail.com 